Received: 10 November 2017

Accepted: 17 April 2018

Published online: 30 April 2018
ENTIFIC REP:RTS

\section{An in vitro transepithelial migration assay to evaluate the role of neutrophils in Respiratory Syncytial Virus (RSV) induced epithelial damage}

\begin{abstract}
Yu Deng ${ }^{1,2}$, Jenny A. Herbert ${ }^{1}$, Claire M. Smith ${ }^{1}$ \& Rosalind L. Smyth ${ }^{1}$
Large numbers of neutrophils migrate into the lungs of children with severe Respiratory Syncytial Virus (RSV) disease. It is unclear how these cells contribute to viral clearance and recovery from infection or whether they contribute to disease pathology. We have developed a novel in vitro model to study neutrophil migration through airway epithelial cells (AECs), the main cellular target of RSV infection. Our model reproduces a physiologically relevant cell polarity and directionality of neutrophil migration. Using this model, we found that RSV infected AECs induced rapid neutrophil transepithelial migration. We also detected increased AEC damage associated with RSV infection, with a further increase in epithelial cells shedding from the Transwell membrane following neutrophil migration. This was not observed in the mock infected controls. Neutrophils that migrated through the RSV infected AECs showed increased cell surface expression of CD11B and MPO compared to neutrophils that had not migrated. In conclusion, our in vitro co-culture assay can be used to identify critical mechanisms that mediate epithelial cell damage and promote inflammation in children with severe RSV disease.
\end{abstract}

Respiratory syncytial virus (RSV) is the leading cause of hospitalisation of infants in the developed world, causing bronchiolitis and severe lower respiratory tract disease in infants and young children ${ }^{1}$. There is currently no vaccine to prevent RSV infection and no specific anti-viral treatment.

The main target for RSV infection is the airway epithelial cells (AECs), specifically ciliated AECs ${ }^{2,3}$. Infection of AECs with RSV induces the production of pro-inflammatory mediators, including pro-inflammatory cytokines IL-6 and chemotactic cytokines CXCL8 (IL-8) and CXCL10 (IP-10), which lead to the recruitment of immune cells, including neutrophils ${ }^{4-6}$.

Neutrophils are an important part of innate host defence against RSV infection and are rapidly recruited to the airways to migrate from the basal sub-epithelial space across the epithelium to the airways following infection ${ }^{7}$. Massive pulmonary neutrophil infiltration is observed in paediatric patients with severe RSV induced bronchiolitis $^{8,9}$. In one study, neutrophils accounted for $76 \%$ of infiltrated cells in the lower airways and $93 \%$ in the upper airways $^{8}$. The mechanisms by which neutrophils migrate across lung epithelia are unclear and a better understanding of this process will likely provide new insights into novel treatment strategies.

A major obstacle to research in this area is a lack of appropriate models. Animal models of RSV infection often do not accurately reproduce the pathology of disease seen during human infection ${ }^{10}$. Very high viral doses are often required for any clinical symptoms to occur ${ }^{10}$. Furthermore, as severe RSV bronchiolitis is most prevalent in infants under 5 months of age ${ }^{11}$, there are ethical and technical limitations for clinical studies to collect appropriate samples.

${ }^{1}$ Respiratory, Critical Care \& Anaesthesia, Great Ormond Street Institute of Child Health, University College London (UCL), London, United Kingdom. ${ }^{2}$ Department of Respiratory medical centre, Chongqing Key Laboratory of Child Infection and Immunity, Children's Hospital of Chongqing Medical University, China International Science and Technology Cooperation base of Child development and Critical Disorders, Ministry of Education Key Laboratory of Child Development and Disorders, Chongqing, 400014, China. Yu Deng and Jenny A. Herbert contributed equally to this work. Correspondence and requests for materials should be addressed to C.M.S. (email: c.m.smith@ucl.ac.uk) 
A number of in vivo and in vitro methods have been used to study the responses of airway epithelium to RSV infection ${ }^{2,10,12,13}$. Cell culture systems provide important insights into host pathogen interactions. However, a fairly inexpensive in vitro model that enables the investigator to experimentally manipulate the viral infection, epithelial barrier, and/or neutrophil in a well-controlled, highly reproducible system is needed. This would be similar to that developed to model intestinal epithelial and lung epithelial responses to bacterial pathogens ${ }^{14-21}$, which use cells lines to model the epithelial monolayer. More recently a model has also been developed studying neutrophil migration during bacterial infection using primary airway epithelial cells ${ }^{22}$.

Here, we describe the development of a co-culture assay system to study the consequences of neutrophil trans-epithelial migration in the physiologically relevant basolateral to apical direction in response to RSV infection of the airways.

\section{Methods}

Participants. Peripheral blood was taken from healthy adult donors at UCL GOS Institute of Child Health. Written informed consent was obtained from all donors prior to their enrolment in the study. Study approval was obtained from the UCL Research Ethics Committee (4735/002). All methods were performed in accordance with the relevant guidelines and regulations.

Epithelial cell culture. Human type-2 alveolar basal epithelial cells (A549) (ATCC CCL-185) were maintained in growth medium (RPMI Glutamax (Life Technologies) supplemented with $5 \% \mathrm{v} / \mathrm{v}$ newborn calf serum (NCS) (Life Technologies), $1 \mathrm{mM}$ L-glutamine (L-glut) (Life Technologies) and $1 \times$ Penicillin/streptomycin (Life Technologies)). HEp-2 cells (ATCC CCL-23) were maintained in Opti-MEM media (Life Technologies) supplemented with $10 \% \mathrm{v} / \mathrm{v}$ NCS, $1 \mathrm{mM}$ L-glut and $1 \times$ Penicillin streptomycin.

Virus purification and quantification. Recombinant GFP tagged RSV A2 strain was kindly provided by Fix et al. ${ }^{23}$. Viral propagation was performed in HEp-2 cells (MOI 0.1) for 3-5 days in Opti-MEM with $1 \mathrm{mM}$ L-glut and $2 \%$ NCS. Infected cells were lysed in a sonicating water bath (Grant, XUBA1), followed by centrifugation at $1200 \mathrm{rpm}$ for 5 minutes. Supernatant was collected and virus concentrated and purified as described previously ${ }^{24}$. Briefly, virus was purified by centrifugation through a polyethersulphone membrane with a pore size of 1000000 Daltons MWCO (1000 kD) (Vivaspin-20, Vivascience, Gloucester, UK). Virus was collected in RPMI (Life Technologies), aliquoted and frozen at $-80^{\circ} \mathrm{C}$. Viruses were quantified by plaque assay. Briefly, $2.5 \times 10^{4}$ HEp-2 cells were seeded into a 96 well plate and cultured overnight in Opti-MEM plus supplements (as above) at $37^{\circ} \mathrm{C} 5 \% \mathrm{CO}_{2}$. The following day cells were washed in PBS and serial tenfold dilutions of viral stock added to triplicate wells $(50 \mu \mathrm{l})$ for 2 hours at $37^{\circ} \mathrm{C} 5 \% \mathrm{CO}_{2}$. The inoculum was replaced with $200 \mu \mathrm{l}$ of Opti-MEM for 24-48 hours at $37^{\circ} \mathrm{C}$ and $5 \% \mathrm{CO}_{2}$. Images of the whole well were captured using a Nikon Eclipse Ti-U microscope equipped with Hamamatsu ORCA 4.0 camera and fluorescence FITC filter. The number of viral plaques from each well were counted and $\mathrm{pfu} / \mathrm{ml}$ was calculated by multiplying the plaques/well by dilution factor and x10.

Neutrophil isolation and purification. Neutrophils were isolated from peripheral venous blood using a Percol density gradient as described previously ${ }^{25}$. A further purification step was performed using the EasySep ${ }^{\text {TM }}$ Human Neutrophil Enrichment Kit (STEMCELL Technologies) as per the manufacturer's instructions ${ }^{26}$. Neutrophils were resuspended in Hanks balanced salt solution (HBSS ${ }^{-}$) without calcium and magnesium (Life Technologies) and FACS analysis was performed using Anti-Human CD49d-APC (BioLegend, 304307) and Anti-Human CD66a/c/e AlexaFluor-488 (BioLegend, 342306) antibodies to confirm purity. Prior to migration, neutrophils were stained with a CellTrace Calcein Red-Orange cell stain (Thermo Fisher) as per the manufacturer's instructions. Stained neutrophils were washed twice in $\mathrm{HBSS}^{-}$then resuspended in HBSS plus calcium and magnesium $\left(\mathrm{HBSS}^{+}\right.$). Unstained neutrophils were used if downstream analysis was to be performed (FACS/ microscopy), these were resuspended in $\mathrm{HBSS}^{+}$prior to migration.

RSV infection of AECs and transepithelial neutrophil migration. A schematic diagram of our neutrophil migration assay is shown in Fig. 1 . A549 cells $\left(1 \times 10^{5}\right)$ were seeded on the underside of a 24 well PET transwell $\left(8 \mu \mathrm{m}\right.$ pore membrane) for 4 hours at $37^{\circ} \mathrm{C}, 5 \% \mathrm{CO}_{2}$. Transwells were then inverted and maintained in growth medium (as above) until confluent (Figure S1A). Cells were then rinsed with PBS and infected with recombinant GFP tagged RSV A2 strain ${ }^{23}$ at MOI 1, or mock infected (RPMI only) for 2 hours at $37^{\circ} \mathrm{C}, 5 \% \mathrm{CO}_{2}$. The inoculum was then removed and Transwells were rinsed with RPMI then placed into RPMI $+1 \%$ FBS for up to 96 hours.

Transwells were placed in a new ultra-low binding 24 well plate (Corning, Costar). $350 \mu$ of $\mathrm{HBSS}^{+}$or infection media (media collected from AECs) was added to the bottom (apical side) and $5 \times 10^{5}$ neutrophils in $\mathrm{HBSS}^{+}$were added to the top (basolateral side) of each Transwell. As a positive control, 100nM N-Formylmethionine-leucyl-phenylalanine (fMLP, Sigma) in $350 \mu \mathrm{l}$ of HBSS + was added to the apical side of the cells. All neutrophils were allowed to migrate for 1 and 4 hours. Neutrophils were then collected for downstream analysis.

Quantification of neutrophil numbers. Non-migrated and migrated neutrophils were placed in triplicate into a 96 well flat bottom ultra-low binding plate (Corning, Costar and were quantified using a fluorescence plate reader (ex $584 \mathrm{~nm} / \mathrm{em} 612 \mathrm{~nm}$ ) (FLUOstar OPTIMA, BMG). Total neutrophils numbers were extrapolated from a standard curve of known numbers of fluorescent neutrophils, starting at $2.5 \times 10^{5}$ in two fold serial dilutions. At least three biological replicas were performed for each group. Differences between Mock and RSV infected group were analysed using a non-parametric Mann-Whitney t-test (GraphPad Prism v5.0). 
A

Cell preparation and infection

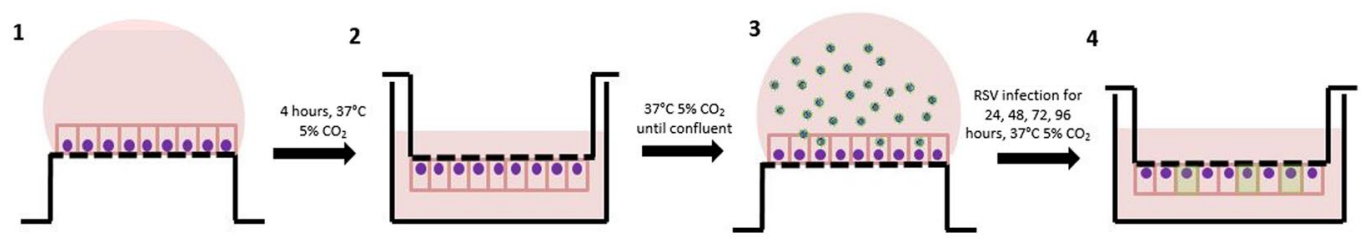

B

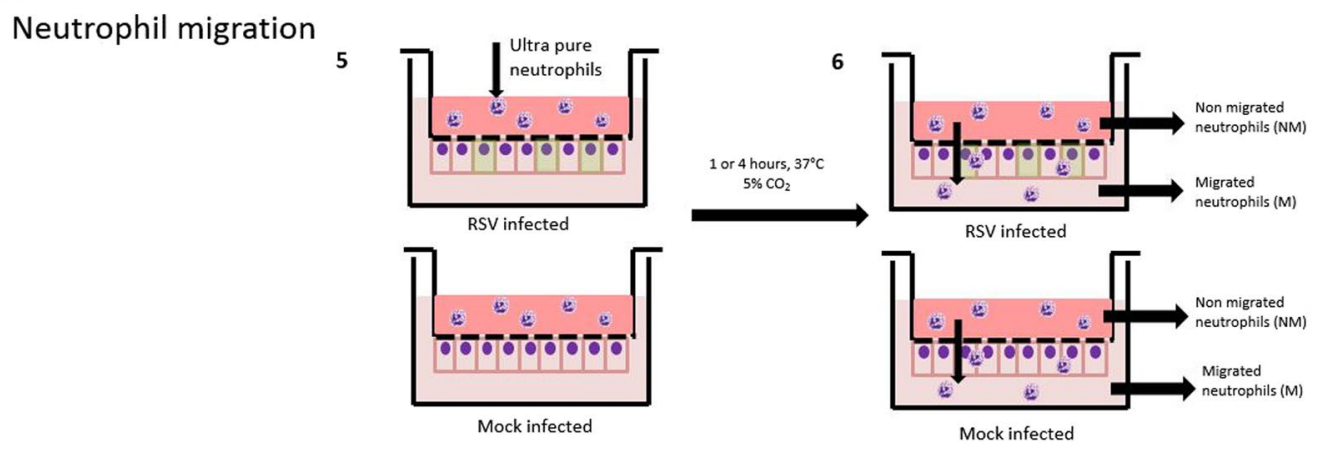

Figure 1. Schematic diagram of neutrophil migration model. Diagram of cell seeding, A549 infection (A) and neutrophil migration (B). (1) A549 cells were seeded onto the underside of a transwell and allowed to attach for 4 hours. (2) Transwells were subsequently inverted and maintained in media to allow a confluent epithelial monolayer to develop for 72 hours. (3) Transwell were inverted and infected with GFP RSV or mock infected for 2 hours. (4) Transwells were inverted and maintained in media and infection allowed to progress for 24, 48, 72 or 96 hours. (5) Ultrapure neutrophils were added to the basolateral side of the transwell, and were allowed to migrate for 1 or 4 hours. Underneath the transwell was HBSS + or RSV infection media. (6) Post migration basolateral and apical neutrophils were collected and downstream analysis performed.

Quantification of viral replication. Fluorescence microscopy was used to visualise GFP RSV infected cells. Cells were fixed with $1 \%(\mathrm{v} / \mathrm{v})$ paraformaldehyde (PFA) for 10 minutes at room temperature, washed twice in PBS, followed by incubation with $50 \mu \mathrm{l}$ of Hoechst stain (ThermoFisher) for 10 minutes at room temperature in the dark and washed once with sterile water. Membranes were removed from the transwell using a scalpel and mounted onto a glass microscope slide. Images were taken using a fluorescence microscope (Nikon Eclipse Ti-U) equipped with x20 objective and a Hamamatsu ORCA 4.0 camera and fluorescence DAPI and FITC filter.

RNA was extracted from A549 cells using an RNeasy RNA extraction kit (Qiagen) as per the manufacturer's instructions. Cells were lysed directly on the membrane using RLT buffer. A DNase step was performed after RNA isolation using the TURBO DNA-free (Ambion) as per the manufacturer's instruction to remove any contaminating DNA. RNA was quantified using the Nanodrop 1000 (ThermoFisher) and quality assessed using the Bioanalyser (Agilent). cDNA was synthesised using the High-Capacity RNA-to-cDNA kit (Applied Biosystems) as per the manufacturers instruction. A starting concentration of $0.5 \mu \mathrm{g}$ total RNA was used in a final reaction volume of $20 \mu \mathrm{l}$. A no reverse transcriptase control was also performed to control for remaining contaminating DNA in the RNA preparation. Quantitative RT-PCR was performed using TaqMan Universal Master Mix II, with UNG (Applied Biosystems). A total reaction volume of $20 \mu \mathrm{l}$ was used with $1 \mu \mathrm{l}$ of cDNA per reaction. Primers and probes were used as previously described ${ }^{27}$. Primers were used at a final concentration of $10 \mathrm{mM}$ and probe used at a final concentration of 2pM. Samples were run on an AB Biosystems step one plus RT-PCR machine. Reaction conditions- 1 cycle $50^{\circ} \mathrm{C}$ for 2 minutes, 1 cycle $95^{\circ} \mathrm{C}$ for 10 minutes, 40 cycles $95^{\circ} \mathrm{C}$ for 15 seconds followed by $60^{\circ} \mathrm{C}$ for 1 minute. A plasmid containing the $\mathrm{N}$ protein sequence ${ }^{28}$ was used to quantify the $\mathrm{N}$ protein copy number within cells. RSV load was extrapolated from a standard curve of known N protein copies. Differences in viral load at RSV infection time points was analysed using a paired t-test (GraphPad Prism v5.0).

Quantifying cell damage (epithelial integrity). Cell damage was quantified by Transepithelial electrical resistance (TEER), Red-dextran leakage, lactate dehydrogenase (LDH) release and by counting the number of cells that remained attached to the membrane (fluorescence microscopy). TEER was measured using an EVOM voltohmmeter (World Precision Instruments, Sarasota, FL, USA) after addition of $0.5 \mathrm{ml}$ of culture medium to the apical surface. The concentration of the cytoplasmic enzyme LDH in the apical supernatants was determined using the Pierce LDH Cytotoxicity Assay Kit (Thermo fisher) as per the manufacturer's instructions. Absorbance $(490 \mathrm{~nm})$ was measured using a plate reader (FLUOstar OPTIMA, BMG). Each sample was run in duplicate or triplicate depending on the amount of sample. Differences between Mock and RSV infected group were analysed by unpaired t-test. 
Permeability of A549 monolayer was determined by flux of Texas red-conjugated 3-kDa dextran (Invitrogen, Camarillo, CA) from the apical to the basal chamber. In brief, after neutrophils had been allowed to migrate for 1 or 4 hours, transwell inserts were moved to a fresh 24 -well plate containing $450 \mathrm{ul}$ of pre-warmed HBSS in the outer chamber. Texas red-conjugated $3-\mathrm{kDa}$ dextran solutions $(5 \mathrm{mg} / \mathrm{mL}$ in $\mathrm{HBBS}$ ) were added to the basolateral side of the epithelial cell layer and incubated at $37^{\circ} \mathrm{C}$. After $2 \mathrm{~h}$ incubation, inserts were removed and three $100 \mathrm{ul}$ aliquots were transferred to a 96 -well plate. The concentration of Texas red-conjugated 3-kDa dextran was calculated from the amount of fluorescence emission at $610 \mathrm{~nm}$ (excitation at $587 \mathrm{~nm}$ ) using a titration curve of known concentration of the same tracers. The results were expressed as the percentage of mock group.

The number of epithelial cells and neutrophils remaining on the PET Transwell membrane post RSV infection and post neutrophil migration was determined using fluorescence microscopy. Membranes were fixed with $1 \%$ $(\mathrm{v} / \mathrm{v})$ paraformaldehyde (PFA) for 10 minutes at room temperature, washed twice in PBS and incubated with $50 \mu \mathrm{l}$ of Hoechst stain (ThermoFisher) for 10 minutes at room temperature in the dark. Membranes were washed once with sterile water, removed from the Transwell using a scalpel and mounted onto a glass microscope slide. At least five Images were acquired from each slide using a confocal microscope (Zeiss LSM710) under a x40 objective. Areas were chosen where no cell clumps were observed as these prevented individual nuclei from being counted. The number of DAPI stained epithelial and neutrophil nuclei in each image were counted using the ImageJ counting tool.

Cytokine production. CXCL8 (IL-8) and IL-6 levels in apical supernatants were quantified using DuoSet ELISAs (R\&D systems) as per the manufacturer's instruction. Each sample was run in duplicate and at least three biological replicas were performed for each group. Differences between Mock and RSV infected group were analysed by unpaired t-test.

Neutrophil CD11B and MPO expression. The amount of neutrophil activation was determined by measuring the cell surface protein expression levels of CD11B and myeloperoxidase (MPO). Neutrophils that were not used for migration experiments were used as a negative control. All neutrophils were centrifuged at $1400 \mathrm{rpm}$, 5 mins and washed once in $500 \mu$ FACS buffer (PBS $\left(\mathrm{Ca}^{2+} \mathrm{Mg}^{2+}\right.$ free), $0.5 \%$ Bovine serum albumin (BSA), $2.5 \mathrm{mM}$ EDTA). The cell pellet was then resuspended in $50 \mu \mathrm{l}$ (1/50 dilution in FACS buffer) of TruStain FcX blocker antibody (BioLegend) and incubated at $4{ }^{\circ} \mathrm{C}$ for 10 minutes, then washed In FACS buffer as noted above. Cells were resuspended in $50 \mu \mathrm{l}$ FACS buffer plus 1/250 dilution PE anti-Human CD11b conjugate (50-0118-T100, Insight Biotechnology) and 1/50 dilution Anti-MPO-APC human antibody (130-107-177, clone: REA491, Miltenyl Biotec) and incubated at $4{ }^{\circ} \mathrm{C}$ for 20 minutes in the dark. Unstained and single antibody controls were performed and confirmed no cross reactivity. Cells were washed once in FACS buffer, resuspended in 1\% PFA and stored at $4^{\circ} \mathrm{C}$. Directly prior to running, samples were centrifuged $(1400 \mathrm{rpm})$ and resuspended in FACS buffer.

Samples were analysed using a Beckton Dickenson LSR II flow cytometer and FlowJo v10.0 FACS analysis software. Neutrophils were first identified as being $\mathrm{CD} 11 \mathrm{~b}$ positive $(\mathrm{PE}+)$. Using this population the geometric mean fluorescence intensity of this population for PE and APC were calculated. Statistical analysis was preformed using a paired t-test (GraphPad Prism v5.0).

\section{Results}

Characterisation of in vitro transepithelial neutrophil migration model. In order to compare this infection model to those previously reported, initial experiments were performed to assess viral replication, epithelial monolayer integrity and inflammatory response. As predicted, we observed an increase $(\mathrm{P}<0.05)$ in fluorescence in GFP-RSV infected transwells over time (Fig. $2 \mathrm{~A}$ and C) from a mean \pm SEM of 7.8. \pm 0.7 arbitrary units at 24 hours post infection to $19.2 \pm 1.4$ at 72 hours and $20.3 \pm 1.0$ at 96 hour post infection (Fig. 2C). No GFP fluorescence was detected in mock infected transwells at all time points tested (Fig. 2B). The increase in GFP fluorescence correlated with an increase in RSV N-protein copy number (Fig. 2D). These data showed that viral load significantly $(\mathrm{P}<0.05)$ increased from 24 to $72 \mathrm{~h}$ and $96 \mathrm{~h}$ post RSV infection. Previous data generated in our lab has also indicated viral load peaks at 72 hours post RSV infection ${ }^{29}$.

RSV infection also resulted in significant damage to the A549 cell monolayer with a significant $(\mathrm{P}<0.05)$ reduction in the number of epithelial cells that remained attached to the Transwell compared to the mock infected control (Fig. 2E). We observed a decrease in number of DAPI stained epithelial cell nuclei between $24(21.0 \pm 1.7)$ and 48 hours $(16.1 \pm 0.6), 72$ hours $(16.0 \pm 0.5)$ and 96 hours $(15.4 \pm 0.4)$ post RSV infection, suggesting fewer cells remain on the membrane after 24 hours. We also detected a significant $(\mathrm{P}<0.05)$ increase in $\mathrm{LDH}$ release ( 2.9 fold increase) after 72 hours infection. The LDH release in the mock controls remained stable at 24,48 , and 72 hours post infection. RSV infection of AECs has also been shown to decrease TEER of epithelial monolayers ${ }^{30}$, however we did not detect a significant change in TEER between the time points (Fig. 2E).

A characteristic of RSV infection is the production of large amounts of chemokines and cytokines ${ }^{5,6,29}$. We also found that the amount of CXCL8 (IL-8) and IL-6 in supernatants significantly $(\mathrm{P}<0.05)$ increased following RSV infection compared to the mock controls (Fig. 2F). We also found that the amount of IL-8 significantly $(\mathrm{P}<0.05)$ increased between 24 hours $(12.8 \pm 3.4 \mathrm{ng} / \mathrm{ml})$ and 72 hour $(20.8 \pm 4.7 \mathrm{ng} / \mathrm{ml})$ post RSV infection.

RSV infection increases neutrophil transepithelial migration. The number of neutrophils that migrated to the apical side of AECs after 1 hour significantly $(\mathrm{P}<0.05)$ increased with RSV infection $(11.5 \pm 1.7 \%)$ compared to mock infected control $(3.8 \pm 0.8 \%)$ (Fig. $3 \mathrm{~A})$. This was found at all time points post-RSV-infection $(24,48,72$ and 96 hours) compared to their respective mock control (Fig. 3A-D) when conditioned supernatant (collected from cells prior to migration) was used. There was no significant change in the numbers of migrated neutrophils between the RSV and mock infected AECs when HBSS + was used. This indicates that the presence of factors secreted into the supernatant during RSV infection are important for neutrophil migration. 


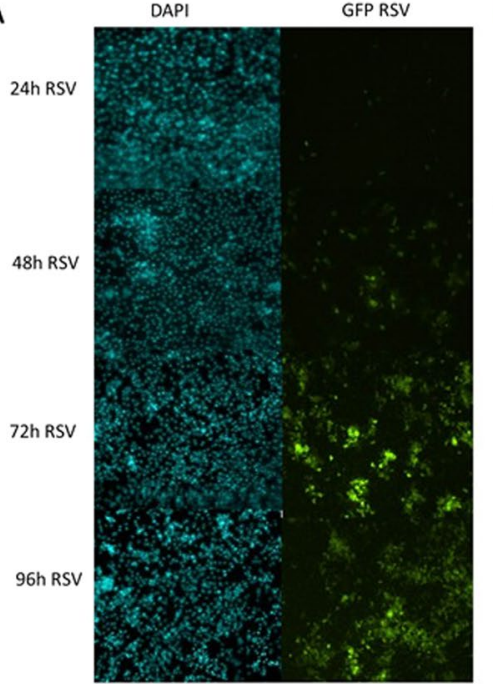

B 72h mock

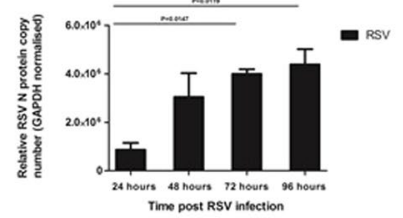

D

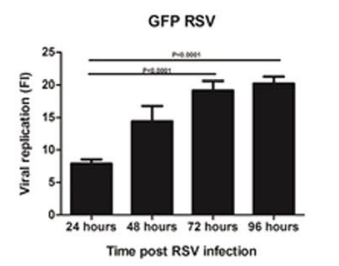

F
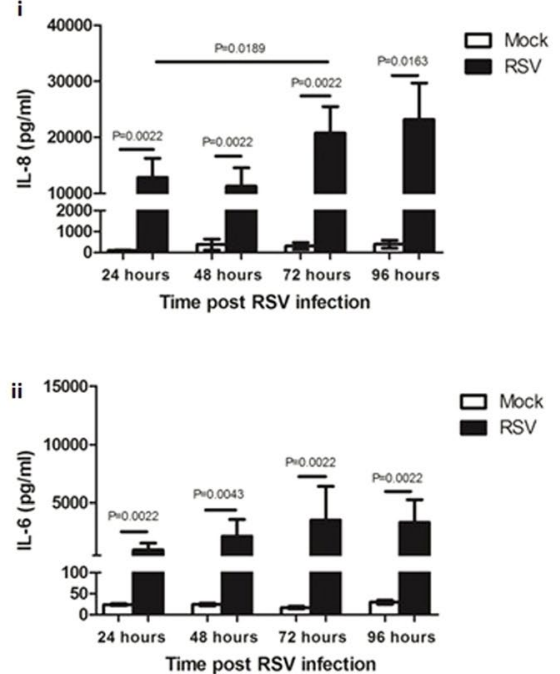

E

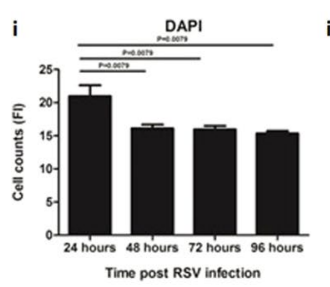

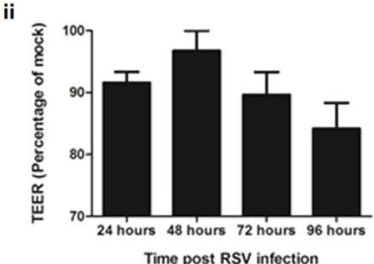

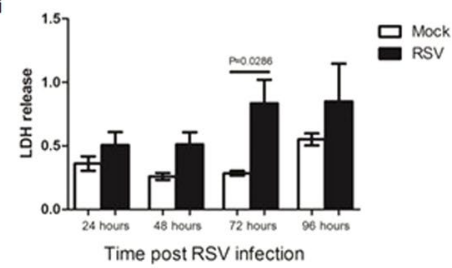

Figure 2. Characterisation of our RSV infection model. (A) Representative microscopy images of RSV infected A549 epithelial monolayer with green fluorescence (GFP) and DAPI fluorescence over time. (B) Representative microscopy images of mock infected A549 monolayer with GFP and DAPI fluorescence at $72 \mathrm{~h}$ post infection. No GFP fluorescence is observed in these controls. (C) Quantitative analysis of the images shown in Fig. 2A. GFP and DAPI fluorescence intensity was quantified using ImageJ, at least 4 images were used for each time point. Bars show mean \pm SEM. Statistical significance is shown. (D) Quantitative RT-PCR of RSV viral load in A549 cells as measured by N protein copy number. Viral load was measure in A549 cells infected with GFP RSV over time. Bars show mean \pm SEM of $\mathrm{n}=3$ biological repeats. Statistical significance is shown. (E) The damage caused to the A549 epithelium following RSV infection for 24, 48, 72 and 96 hours as determined by (i) number of epithelial nuclei/cell remaining attached to the membrane based on DAPI staining $/ 0.045 \mathrm{~mm}^{2}$ (ii) TEER as measured using a voltohmmeter, data is represented as the percentage relative to the mock infected control (iii) Lactate dehydrogenase (LDH) release as measured in supernatant of AECs post RSV infection. Statistical significance is shown. Bars show mean \pm SEM of at least $\mathrm{n}=3$ biological repeats. (F) CXCL8 (IL-8) and IL-6 concentrations in supernatants post RSV and mock infection of A549 cells as measured by ELISA. Bars show mean \pm SEM of $n=3$ biological repeats. Statistical significance is shown. For all other comparisons $P>0.05$.

RSV infection increased neutrophil migration in a time dependent manner (Table 1 and Figure S3/S4). After 1 hour a mean of $5.7 \times 10^{4}$ neutrophils/well had migrated through RSV infected epithelial cells at 24 hours, $9.9 \times 10^{4}$ at 48 hours, $1.1 \times 10^{5}$ at 72 hours and $1.8 \times 10^{5}$ at 96 hours post RSV infection, but the difference between these time points was not significant. The number of migrated neutrophils in the respective mock controls remained constant between $1.9 \times 10^{4}$ and $2.3 \times 10^{4}$ at 24 and 96 hours, respectively. After 4 hours the number of migrated neutrophils was slightly increased $(\mathrm{P}>0.05)$ with counts of $1.1 \times 10^{5}, 1.4 \times 10^{5}, 1.3 \times 10^{5}$ and $2.6 \times 10^{5}$ neutrophils/well at 24,48 , 72 and 96 hours post RSV-infection respectively. As before, the number of migrated neutrophils in the mock controls remained constant between $6.1 \times 10^{4}$ and $8.4 \times 10^{4}$ at 24 and 96 hours, respectively (Fig. 3).

Migrated neutrophils express higher levels of CD11b and MPO in response to RSV infection compared to non-migrated neutrophils. Expression of $\mathrm{CD} 11 \mathrm{~B}$ and MPO was significantly $(\mathrm{P}<0.05)$ increased on neutrophils that had migrated through RSV infected AECS after 1 hour compared to neutrophils that migrated through the mock infected AECs (Fig. 4). This was observed at $24 \mathrm{~h}$ and $72 \mathrm{~h}$ post-RSV infection (Fig. 4). CD11B has been used previously as a marker of neutrophil transmigration and MPO a marker of neutrophil activation ${ }^{31}$.

We also found that expression of both $\mathrm{CD} 11 \mathrm{~B}$ and MPO was significantly $(\mathrm{P}<0.05)$ increased on neutrophils that had migrated through epithelial cells infected with RSV for 24 hour compared to non-migrated neutrophils (Fig. 5A). We also found that expression of $\mathrm{CD} 11 \mathrm{~B}$, but not $\mathrm{MPO}$, was significantly $(\mathrm{P}<0.05)$ increased in neutrophils which had migrated through AECs infected with RSV for 72 hour compared to non-migrated neutrophils after 1 hour (Fig. 5B). 
A

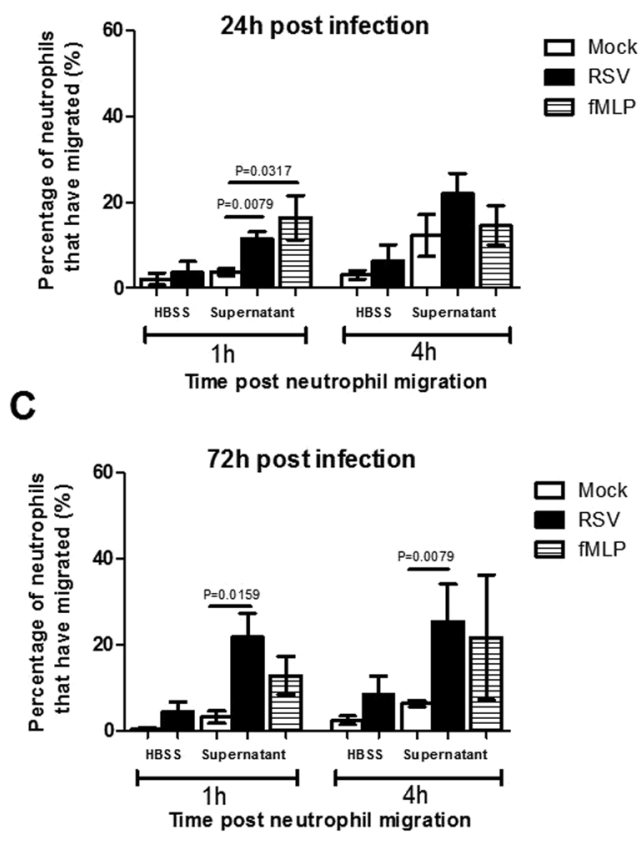

B
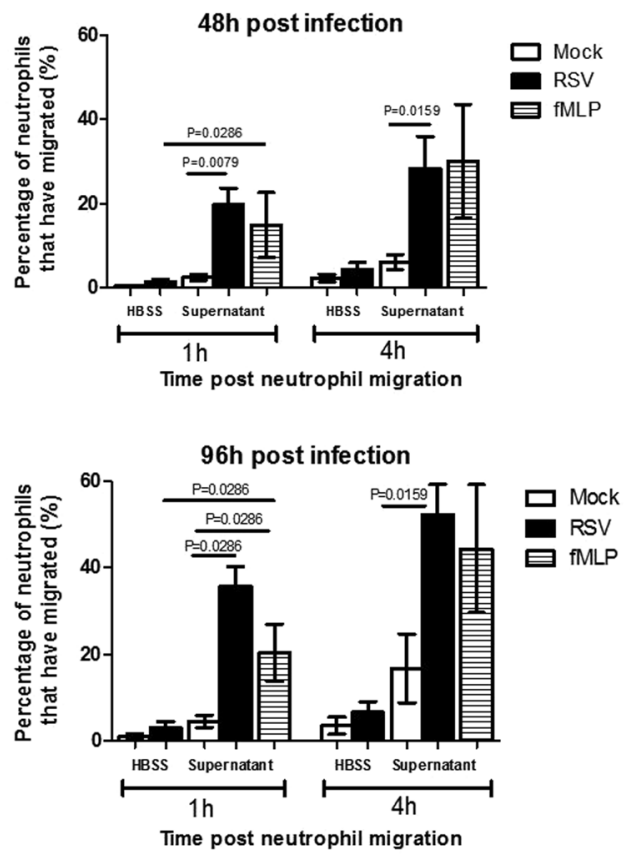

Figure 3. RSV increases the numbers of neutrophils that migrate through infected A549 monolayers The percentage of neutrophils that migrated through mock and RSV infected A549 monolayers after (A) 24 hours, (B) $48 \mathrm{~h}$, (C) $72 \mathrm{~h}$ or (D) 96 hours post-infection was quantified. Neutrophils were exposed to infected A549 epithelial cells submerged in fresh $\mathrm{HBSS}^{+}$or the conditioned supernatant produced from the same cells prior to migration (RSV and mock infected). The neutrophil chemoattractant N-Formylmethionine-leucylphenylalanine (fMLP) was used as a positive control. Bars show mean \pm SEM of $n=3 / 4$ biological repeats. Statistical significance is shown. For all other comparisons $\mathrm{P}>0.05$.

\begin{tabular}{|l|l|c|l|l|l|}
\hline \multirow{2}{*}{$\begin{array}{l}\text { Time } \\
\text { P.I }\end{array}$} & \multirow{2}{*}{$\begin{array}{l}\text { Time } \\
\text { P.N }\end{array}$} & Mock infected & \multicolumn{2}{l|}{ RSV infected } \\
\cline { 2 - 6 } & HBSS ++ & $\begin{array}{l}\text { Conditioned } \\
\text { Media }\end{array}$ & HBSS++ & $\begin{array}{l}\text { Conditioned } \\
\text { Media }\end{array}$ \\
\hline \multirow{2}{*}{$24 \mathrm{H}$} & $1 \mathrm{~h}$ & $3655 \pm 1573$ & $19231 \pm 10628$ & $17947 \pm 10605$ & $\mathbf{5 1 7 4 9} \pm \mathbf{1 5 7 2 6 *}$ \\
\cline { 2 - 6 } & $4 \mathrm{~h}$ & $21341 \pm 30410$ & $37403 \pm 14484$ & $39491 \pm 42521$ & $92448 \pm 42912$ \\
\hline \multirow{2}{*}{$48 \mathrm{H}$} & $1 \mathrm{~h}$ & $2796 \pm 1721$ & $12442 \pm 10079$ & $14608 \pm 9045$ & $\mathbf{9 6 2 8 2} \pm \mathbf{5 0 2 3 2 *}$ \\
\cline { 2 - 6 } & $4 \mathrm{~h}$ & $8748 \pm 6668$ & $102918 \pm 134198$ & $25209 \pm 17761$ & $156386 \pm 90975$ \\
\hline \multirow{2}{*}{$72 \mathrm{H}$} & $1 \mathrm{~h}$ & $2966 \pm 1841$ & $8650 \pm 3801$ & $15544 \pm 8985$ & $\mathbf{1 0 2 7 0 8} \pm \mathbf{6 8 6 7 2}$ \\
\cline { 2 - 6 } & $4 \mathrm{~h}$ & $28437 \pm 23953$ & $31041 \pm 9711$ & $54116 \pm 42995$ & $136580 \pm 109902$ \\
\hline \multirow{2}{*}{$96 \mathrm{H}$} & $1 \mathrm{~h}$ & $6554 \pm 6779$ & $20831 \pm 16748$ & $23480 \pm 18864$ & $\mathbf{2 1 3 9 5 0} \pm \mathbf{8 9 1 2 5 *}$ \\
\cline { 2 - 6 } & $4 \mathrm{~h}$ & $18156 \pm 17044$ & $97870 \pm 95784$ & $37029 \pm 28396$ & $\mathbf{2 8 7 3 7 4} \pm \mathbf{6 0 1 6 1 *}$ \\
\hline
\end{tabular}

Table 1. Number of migrated neutrophils. P.I indicates post-infection. P.N. indicates post-neutrophil migration. Mean and SD shown $(\mathrm{n}=4)$, boldface and $*$ indicates significant increase in migrated neutrophils compared to respective Mock infected control.

Neutrophil transepithelial migration enhances RSV infection induced epithelial monolayer disruption. To determine whether neutrophil migration enhances the cytopathology of RSV-infection, we measured cell damage in relation to red-dextran leakage (from basolateral to apical compartments), TEER and lactate dehydrogenase (LDH) release into the apical supernatant. We did not detect any significant increase in red-dextran leakage or decrease in TEER following neutrophil migration at 24 hours post RSV infection (Fig. 6A). However, the numbers of epithelial cells present on membrane after neutrophil migration significantly decreased following 24 hours RSV-infection compared to the respective mock controls (Fig. 6B and C). We found that 24 hours post RSV infection, neutrophil migration led to a significant $(\mathrm{P}<0.05) 48 \%$ reduction in the number of AECs present on the membrane compared to the mock control (Fig. 6C). The number of adherent neutrophils also significantly $(\mathrm{P}<0.05)$ decreased with RSV-infection compared to the mock-control (Fig. 6C). These data suggests that the fluorescence microscopy assay (cell adherence) may be a more sensitive method for analyzing cell damage in our model compared to the TEER and LDH methods (Further TEER data is shown in Figure $\mathrm{S} 1 / \mathrm{S} 2)$. 
A

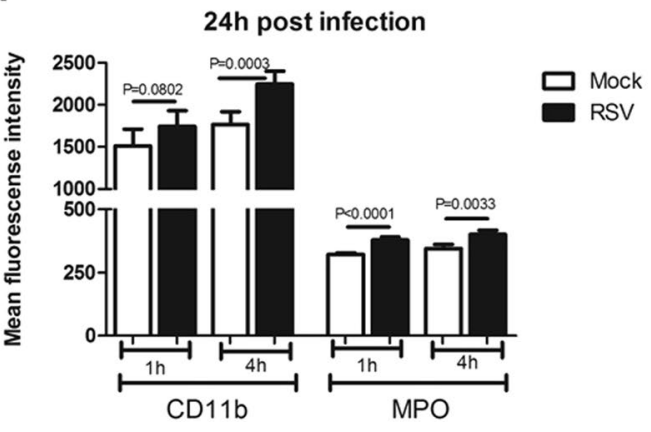

B

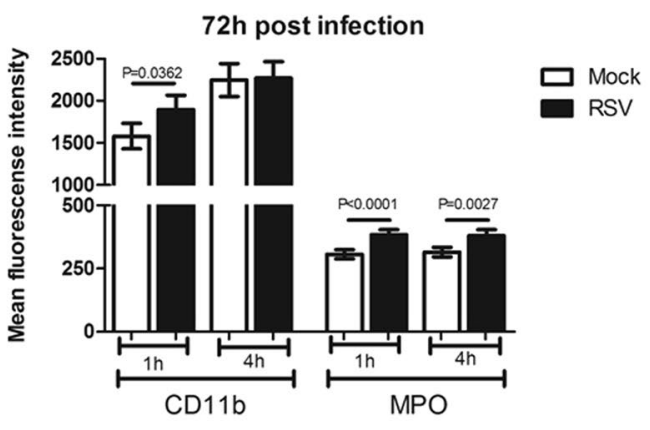

Figure 4. Neutrophil migration through RSV infected monolayers show increased cell surface expression of CD11B and MPO. Neutrophils that migrated through RSV infected epithelial cells infected for (A) 24 hours or (B) 72 hours showed higher cell surface expression of CD11B and MPO compared to those that migrated through mock-infected epithelial cells. Neutrophils were collected from the apical compartments and the percentage stained for cell surface expression of CD11B (PE) and MPO (APC) were determined by flow cytometry. Neutrophils were gated on initially using a PE positive gate. Using this population the geometric mean fluorescence intensity of PE and APC fluorescence was calculated. Neutrophils from the same donor were compared. Bars show mean \pm SEM of $n=4$ biological repeats. Statistical significance is shown. For all other comparisons $\mathrm{P}>0.05$.

A
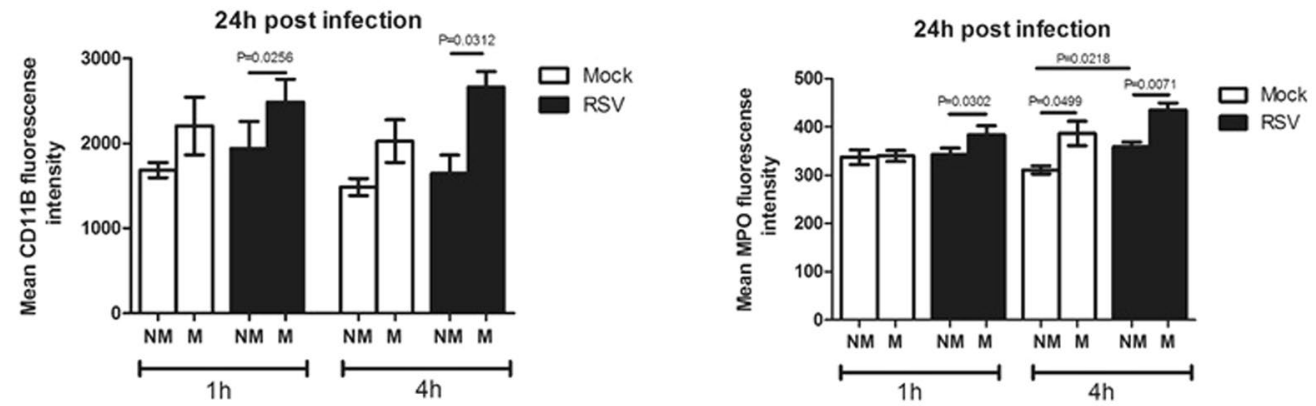

B
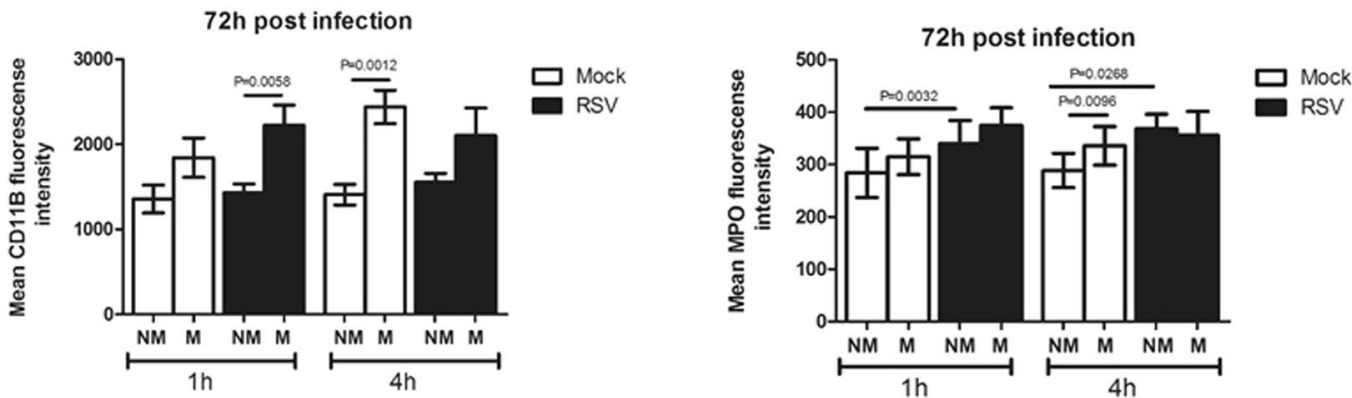

Figure 5. Migrated neutrophils show increased cell surface expression of CD11B and MPO compared to non-migrated neutrophils. Neutrophils that migrated $(M)$ to the apical compartment through RSV infected epithelial cells infected for (A) 24 hours or (B) 72 hours showed higher cell surface expression of i) CD11B and ii) MPO compared to those non-migrated (NM) neutrophils that remain on the basolateral side. The percentage of migrated and non-migrated neutrophils expressing $\mathrm{CD} 11 \mathrm{~B}$ and MPO was calculated by staining for cell surface expression of CD11B (PE) and MPO (APC) were determined by flow cytometry. Neutrophils were gated on initially using a PE positive gate. Using this population the geometric mean fluorescence intensity of $\mathrm{PE}$ and APC fluorescence was calculated. Bars show mean \pm SEM of $n=4$ biological repeats. Statistical significance is shown. For all other comparisons $\mathrm{P}>0.05$. 
A
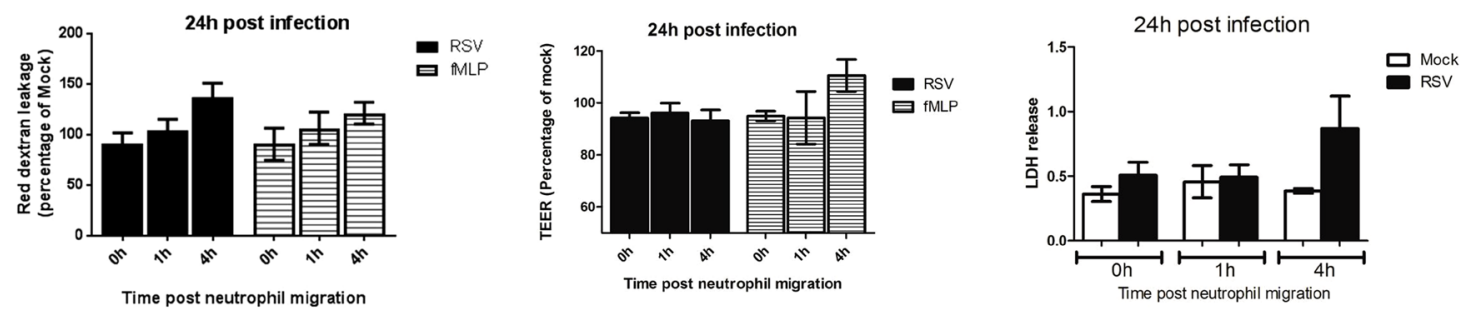

B
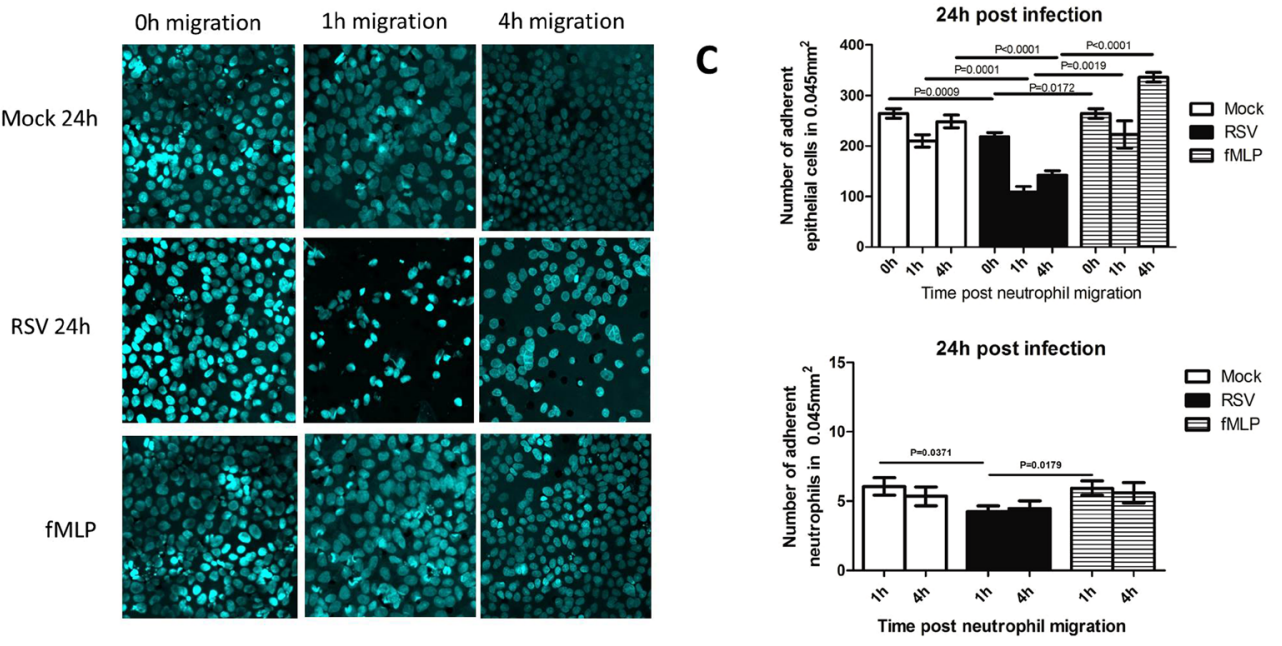

Figure 6. Damage caused by neutrophil migration through epithelial monolayers infected with RSV for 24 hours. (A) The damage caused to the A549 epithelium following neutrophil migration through cells infected with mock or RSV infection for 24 hours as determined by (i) Red-dextran leakage from basal-apical compartments, data represented as the percentage relative to the mock infected control $\mathrm{n}=4$ (ii) TEER as measured using a voltohmmeter, data is represented as the percentage relative to the mock infected control $\mathrm{n}=9$ (iii) Lactate dehydrogenase (LDH) release as measured in apical supernatant of AECs post neutrophil migration. The neutrophil chemoattractant N-Formylmethionine-leucyl-phenylalanine (fMLP) was used as a positive control Bars show mean \pm SEM of at least $\mathrm{n}=3$ biological repeats. (B) Representative microscopy images of A549 epithelial monolayers infected with RSV for 24 hours stained with a nuclei stain (Hoechst) following neutrophil migration after 1 or 4 hours. (C) Epithelial cell and neutrophil nuclei were counted in ImageJ and the average number of nuclei from all images was calculated. Bars show mean \pm SEM of $\mathrm{n}=5$ biological repeats. Statistical significance is shown. For all other comparisons $\mathrm{P}>0.05$.

Airway epithelial cell damage was further increased $(\mathrm{P}<0.05)$ after 72 hours RSV-infection (Fig. 7) compared to 24 hours (Fig. 6) in relation to TEER etc. After 72 hours neutrophil migration (4 hours) resulted in a significant $(\mathrm{P}<0.05)$ increase in red-dextran leakage and LDH release from RSV-infected epithelial cells compared to cultures mock-infected (Fig. 7A). Neutrophil migration (1 and 4 hours) through AECs infected with RSV for 72 hours also led to a significant $(\mathrm{P}<0.05)(1 \mathrm{~h}-46 \%, 4 \mathrm{~h}-41 \%)$ reduction in the number of epithelial cells present on the membrane compared to the mock control (Fig. 7B and C). However, neutrophils that migrated in response to fMLP (positive control) did not affect the numbers of epithelial cells present on membranes compared to mock controls, despite reporting similar levels of neutrophil migration as the RSV infected Transwells (see Fig. 3).

\section{Discussion}

We have developed a novel neutrophil and airway epithelial cell (AEC) co-culture system to explore the effect of neutrophil trans-epithelial migration in response to RSV infection. Our study has revealed valuable new insights into the function and activation of neutrophils that could have significant implications for RSV disease development and severity. Previous in vitro cell culture models using airway and bronchial epithelial cell lines has provided insight into the mechanisms of RSV infection ${ }^{13,30,32-35}$ but these models have used epithelial cell monolayer in the opposite orientation $^{33,34}$, which does not mimic the correct polarity of trans-epithelial migration of neutrophils in vivo. Our inverted epithelial model showed consistent characteristics of RSV infection as traditional epithelial cell models, including RSV replication kinetics, increased inflammatory cytokine production (CXCL8 and IL-6) and epithelial monolayer disruption. Epithelial integrity is a good indication of barrier function and RSV infection is thought to decrease the epithelial monolayer resistance and increase the permeability of polarised AECs ${ }^{30}$. We found increased epithelial cell detachment and increased LDH release after 72 hours RSV infection. This is in agreement with the data performed in other research group using cell lines for RSV infection ${ }^{30}$ and similar to what has been observed in human lungs ${ }^{36}$. Under these conditions, the epithelium is compromised in its defensive functions and therefore 72 hours post RSV infection was chosen as an appropriate end point for this study. 
A
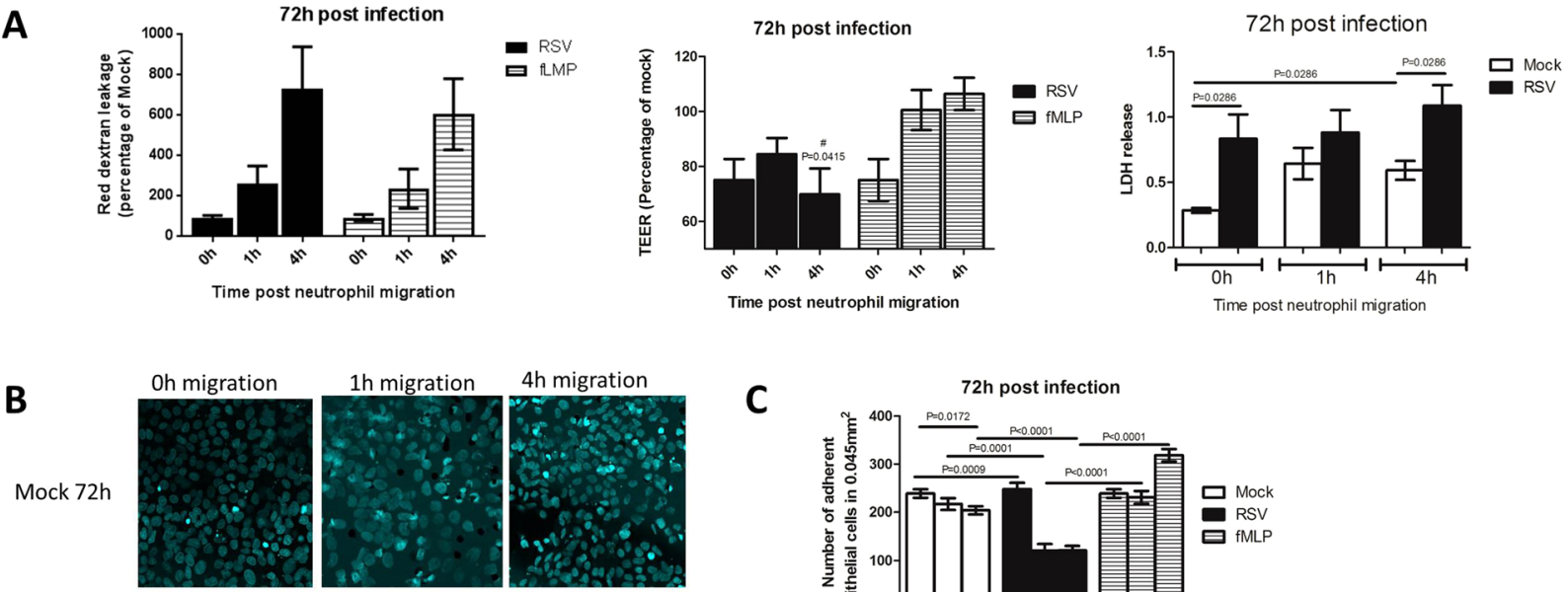

C

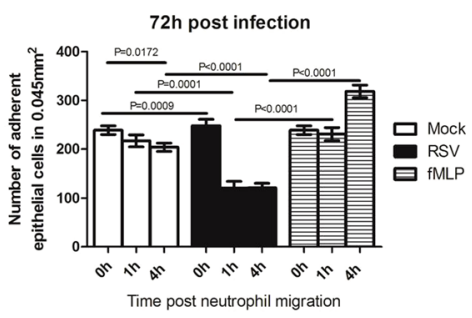

RSV $72 h$
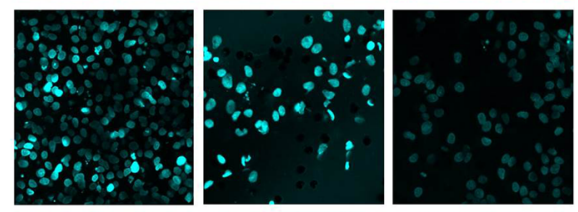

Time post neutrophil migration

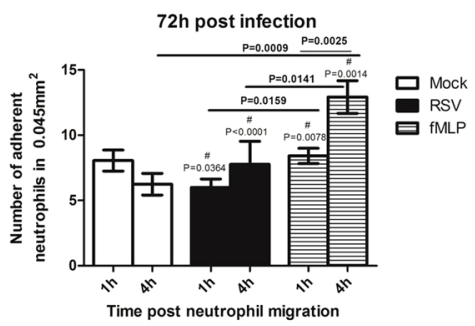

Figure 7. Neutrophil migration increases damage to epithelial monolayers infected with RSV for 72 hours. (A) The damage caused to the A549 epithelium following neutrophil migration through cells infected with mock or RSV infection for 72 hours as determined by i) Red-dextran leakage from basal-apical compartments, data represented as the percentage relative to the mock infected control $n=4$ ii) TEER as measured using a voltohmmeter, data is represented as the percentage relative to the mock infected control $n=9$ iii) Lactate dehydrogenase (LDH) release as measured in apical supernatant of AECs post neutrophil migration. The neutrophil chemoattractant N-Formylmethionine-leucyl-phenylalanine (fMLP) was used as a positive control. Bars show mean \pm SEM of at least $n=3$ biological repeats. (B) Representative microscopy images of A549 epithelial monolayers infected with RSV for 72 hours stained with a nuclei stain (Hoechst) following neutrophil migration after 1 or 4 hours. (C) Epithelial cell and neutrophil nuclei were counted in ImageJ and the average number of nuclei from all images was calculated. Bars show mean \pm SEM of $n=5$ biological repeats. Statistical significance is shown. A hash $(\#)$ indicates a significant $(\mathrm{P}<0.05)$ difference was found when compared to the equivalent data collected at 24 hours post infection (Fig. 6). For all other comparisons $\mathrm{P}>0.05$.

The primary objective of neutrophils is to migrate out of the blood circulation and across a number of tissue barriers and then degranulate, phagocytose and destroy pathogenic microorganisms in the acute inflammatory response ${ }^{37}$. We found that neutrophil trans-epithelial migration was dependent on soluble factors produced by RSV infected AECs. This is in good agreement with previous reports which showed epithelial cells drive active migration through the production of chemoattractants in response to RSV, particularly CXCL8 $8^{38-40}$, which we showed was increased in our infection model. In order to characterise the function of migrated neutrophils, we measured the expression of two important markers of neutrophil activation, CD11B and myeloperoxidase (MPO). Neutrophil transepithelial migration is thought to be exclusively dependent on CD11B $\mathrm{B}^{26,41-43}$, which mediates neutrophil interaction with the basolateral and apical epithelial surface ${ }^{44-47}$. Furthermore, neutrophils isolated from BAL of children with severe RSV disease have increased expression of CD11B compared to neutrophils isolated from the blood ${ }^{31}$. In our model, neutrophil expression of CD11B (Fig. 4) correlated with RSV infection and epithelial cell detachment compared to mock controls. MPO expression was also consistently higher in neutrophils that migrated through RSV infected epithelium compared to mock controls at all time points investigated. MPO serves as an index of neutrophil activation and degranulation ${ }^{48}$ and can influence metabolic reactions as well as the amount and type of oxidants production ${ }^{49,50}$. Increased levels of MPO have been reported in viral infections ${ }^{51}$ and RSV-stimulated neutrophils have been shown to contribute to the pulmonary pathology in RSV bronchiolitis ${ }^{52}$.

We also found that, particularly at the early (24 hours) stage of RSV infection, CD11B and MPO expression was higher in neutrophils that had migrated through RSV infected AECs compared to those that remained on the basolateral side (non-migrated neutrophils) (Fig. 5A). This suggests that transepithelial migration is a key factor in stimulating neutrophil activation marker expression in our model. Interestingly, we found that MPO expression was also increased in non-migrated neutrophils in RSV infected wells compared to non-migrated 
neutrophils in the mock infected controls (Fig. 5B). Non-migrated neutrophils will not be in direct contact with epithelial cells thought to be the target of RSV infection. These data indicates that soluble factors present in the basolateral side of RSV infected epithelial cells may stimulate MPO expression.

Neutrophil migration is thought to occur without inducing any effects on barrier function ${ }^{53,54}$. However in vitro, massive neutrophil migration is associated with enhanced epithelial permeability ${ }^{55,56}$. In our model, neutrophil migration in response to RSV enhanced epithelial damage. Our positive control (fMLP) induced massive neutrophil migration, but did not cause disruption in epithelial layer integrity or increase in cell detachment. This suggests that neutrophil-induced epithelial barrier disruption is dependent on the compromised defensive function of epithelial cells induced by RSV infection. This is consistent with clinical findings that the degree of neutrophilic inflammation correlated with high loads of RSV infection, virus-induced lung injury and disease severity in patients with RSV infection ${ }^{57-61}$.

A549 cells remain a popular choice for studying RSV infection ${ }^{62,63}$. However, compared to other lung epithelial cells, their lower TEER, higher paracellular permeability ${ }^{64}$ and reduced tight junction formation ${ }^{65}$, does limit our interpretation of the epithelial integrity following neutrophil migration and RSV infection. Our TEER readings of $150 \Omega \mathrm{cm}^{2}$ at confluency are lower than those reported for primary cells $\left(>700 \Omega \mathrm{cm}^{2}\right)$ but are higher than those reported by others using A549 cells $\left(<50 \Omega \mathrm{cm}^{2}\right)^{65}$. Therefore we are confident that our cell layer is confluent and that the integrity of the A549 barrier is limited only by the reduced presence of tight junction proteins in these cells. We therefore recommend that future studies aimed at determining changes in the epithelial barrier and role of tight junctions during neutrophil migration should use other lung epithelial cells (i.e Calu-3) or primary lung epithelial cell cultures.

In conclusion, we have developed a physiologically relevant co-culture system to study the role of neutrophils in RSV infection. This model will allow us to identify critical mechanisms that mediate epithelial cell damage and promote inflammation in children with severe RSV bronchiolitis.

\section{References}

1. Nair, H. et al. Global burden of acute lower respiratory infections due to respiratory syncytial virus in young children: a systematic review and meta-analysis. The Lancet 375, 1545-1555 (2010).

2. Villenave, R. et al. Differential cytopathogenesis of respiratory syncytial virus prototypic and clinical isolates in primary pediatric bronchial epithelial cells. Virol J 8, 43 (2011).

3. Zhang, L., Peeples, M. E., Boucher, R. C., Collins, P. L. \& Pickles, R. J. Respiratory syncytial virus infection of human airway epithelial cells is polarized, specific to ciliated cells, and without obvious cytopathology. J Virol 76, 5654-5666 (2002).

4. Pickles, R. J. \& DeVincenzo, J. P. Respiratory syncytial virus (RSV) and its propensity for causing bronchiolitis. J Pathol 235, 266-276 (2015).

5. McNamara, P. S., Flanagan, B. F., Hart, C. A. \& Smyth, R. L. Production of chemokines in the lungs of infants with severe respiratory syncytial virus bronchiolitis. J Infect Dis 191, 1225-1232 (2005).

6. Sheeran, P. et al. Elevated cytokine concentrations in the nasopharyngeal and tracheal secretions of children with respiratory syncytial virus disease. Pediatr Infect Dis J 18, 115-122 (1999).

7. Openshaw, P. J., Chiu, C., Culley, F. J. \& Johansson, C. Protective and Harmful Immunity to RSVInfection. Annual reviews Immunology 501-532 (2017).

8. Everard, M. L. et al. Analysis of cells obtained by bronchial lavage of infants with respiratory syncytial virus infection. Arch Dis Child 71, 428-432 (1994).

9. McNamara, P. S., Ritson, P., Selby, A., Hart, C. A. \& Smyth, R. L. Bronchoalveolar lavage cellularity in infants with severe respiratory syncytial virus bronchiolitis. Arch Dis Child 88, 922-926 (2003).

10. Taylor, G. Animal models of respiratory syncytial virus infection. Vaccine 35, 469-480 (2017).

11. Ajayi-Obe, E. K. et al. Influenza A and respiratory syncytial virus hospital burden in young children in East London. Epidemiol Infect 136, 1046-1058 (2008).

12. Bem, R. A., Domachowske, J. B. \& Rosenberg, H. F. Animal models of human respiratory syncytial virus disease. Am J Physiol Lung Cell Mol Physiol 301, L148-56 (2011).

13. Omar, S. et al. Respiratory virus infection up-regulates TRPV1, TRPA1 and ASICS3 receptors on airway cells. PLoS ONE 12, (2017).

14. Hurley, B. P., Siccardi, D., Mrsny, R. J. \& McCormick, B. A. Polymorphonuclear cell transmigration induced by Pseudomonas aeruginosa requires the eicosanoid hepoxilin A3. J Immunol 173, 5712-5720 (2004).

15. Tamang, D. L. et al. Hepoxilin A(3) facilitates neutrophilic breach of lipoxygenase-expressing airway epithelial barriers. J Immunol 189, 4960-4969 (2012)

16. Mrsny, R. J. et al. Identification of hepoxilin A3 in inflammatory events: a required role in neutrophil migration across intestinal epithelia. Proc Natl Acad Sci USA 101, 7421-7426 (2004).

17. Boll, E. J. et al. Enteroaggregative Escherichia coli promotes transepithelial migration of neutrophils through a conserved 12-lipoxygenase pathway. Cell Microbiol 14, 120-132 (2012).

18. Hurley, B. P., Williams, N. L. \& McCormick, B. A. Involvement of phospholipase A2 in Pseudomonas aeruginosa-mediated PMN transepithelial migration. Am J Physiol Lung Cell Mol Physiol 290, L703-L709 (2006).

19. McCormick, B. A. Bacterial-induced hepoxilin A3 secretion as a pro-inflammatory mediator. FEBS J 274, 3513-3518 (2007).

20. Weppler, A., Rowter, D., Hermanns, I., Kirkpatrick, C. J. \& Issekutz, A. C. Modulation of endotoxin-induced neutrophil transendothelial migration by alveolar epithelium in a defined bilayer model. Exp Lung Res 32, 455-482 (2006).

21. Weppler, A. \& Issekutz, A. C. Alveolar epithelium down-modulates endotoxin-but not tumor necrosis factor alpha-induced activation of endothelium and selectively inhibits neutrophil transendothelial migration. Exp Lung Res 34, 425-453 (2008).

22. Yonker, L. M. et al. Development of a Primary Human Co-Culture Model of Inflamed Airway Mucosa. Sci Rep 7, 8182 (2017).

23. Fix, J., Galloux, M., Blondot, M.-L. \& Eléouët, J.-F. The insertion of fluorescent proteins in a variable region of respiratory syncytial virus L polymerase results in fluorescent and functional enzymes but with reduced activities. Open Virol J 5, 103-108 (2011).

24. Bataki, E. L., Evans, G. S. \& Everard, M. L. Respiratory syncytial virus and neutrophil activation. Clin Exp Immunol 140, 470-477 (2005).

25. Jepsen, L. V. \& Skottun, T. A rapid one-step method for the isolation of human granulocytes from whole blood. Scand J Clin Lab Invest 42, 235-238 (1982).

26. Sabroe, I., Jones, E. C., Usher, L. R., Whyte, M. K. B. \& Dower, S. K. Toll-like receptor (TLR)2 and TLR4 in human peripheral blood granulocytes: a critical role for monocytes in leukocyte lipopolysaccharide responses. J Immunol 168, 4701-4710 (2002).

27. Dewhurst-Maridor, G., Simonet, V., Bornand, J. E., Nicod, L. P. \& Pache, J. C. Development of a quantitative TaqMan RT-PCR for respiratory syncytial virus. J Virol Methods 120, 41-49 (2004). 
28. Castagné, N. et al. Biochemical characterization of the respiratory syncytial virus P-P and P-N protein complexes and localization of the P protein oligomerization domain. J Gen Virol 85, 1643-1653 (2004).

29. Smith, C. M. et al. Ciliary dyskinesia is an early feature of respiratory syncytial virus infection. Eur Respir J 43, 485-496 (2014).

30. Singh, D., McCann, K. L. \& Imani, F. MAPK and heat shock protein 27 activation are associated with respiratory syncytial virus induction of human bronchial epithelial monolayer disruption. Am J Physiol Lung Cell Mol Physiol 293, L436-45 (2007).

31. Halfhide, C. P. et al. Neutrophil TLR4 expression is reduced in the airways of infants with severe bronchiolitis. Thorax 64, 798-805 (2009).

32. Becker, S., Reed, W., Henderson, F. W. \& Noah, T. L. RSV infection of human airway epithelial cells causes production of the betachemokine RANTES. Am J Physiol 272, L512-20 (1997).

33. Stark, J. M., Godding, V., Sedgwick, J. B. \& Busse, W. W. Respiratory syncytial virus infection enhances neutrophil and eosinophil adhesion to cultured respiratory epithelial cells. Roles of CD18 and intercellular adhesion molecule-1. J Immunol 156, 4774-4782 (1996).

34. Wang, S. Z. et al. Neutrophils induce damage to respiratory epithelial cells infected with respiratory syncytial virus. Eur Respir J 12, 612-618 (1998).

35. Arnold, R., Humbert, B., Werchau, H., Gallati, H. \& König, W. Interleukin-8, interleukin-6, and soluble tumour necrosis factor receptor type I release from a human pulmonary epithelial cell line (A549) exposed to respiratory syncytial virus. Immunology $\mathbf{8 2}$, 126-133 (1994).

36. Johnson, J. E., Gonzales, R. A., Olson, S. J., Wright, P. F. \& Graham, B. S. The histopathology of fatal untreated human respiratory syncytial virus infection. Mod Pathol 20, 108-119 (2007).

37. Parkos, C. A. Neutrophil-Epithelial Interactions: A Double-Edged Sword. Am J Pathol 186, 1404-1416 (2016).

38. Abu-Harb, M. et al. IL-8 and neutrophil elastase levels in the respiratory tract of infants with RSV bronchiolitis. Eur Respir J 14, 139-143 (1999)

39. Harrison, A. M., Bonville, C. A., Rosenberg, H. F. \& Domachowske, J. B. Respiratory syncytical virus-induced chemokine expression in the lower airways: eosinophil recruitment and degranulation. Am J Respir Crit Care Med 159, 1918-1924 (1999).

40. Wang, S. Z. \& Forsyth, K. D. The interaction of neutrophils with respiratory epithelial cells in viral infection. Respirology 5, 1-10 (2000)

41. Chin, A. C. \& Parkos, C. A. Pathobiology of neutrophil transepithelial migration: implications in mediating epithelial injury. Annu Rev Pathol 2, 111-143 (2007).

42. Hixenbaugh, E. A. et al. Stimulated neutrophils induce myosin light chain phosphorylation and isometric tension in endothelial cells. Am J Physiol 273, H981-8 (1997).

43. Carolan, E. J. \& Casale, T. B. Neutrophil transepithelial migration is dependent upon epithelial characteristics. Am J Respir Cell Mol Biol 15, 224-231 (1996).

44. Celi, A. et al. ICAM-1-independent adhesion of neutrophils to phorbol ester-stimulated human airway epithelial cells. Am J Physiol 277, L465-71 (1999).

45. Zhou, X. et al. LPS activation of Toll-like receptor 4 signals CD11b/CD18 expression in neutrophils. Am J Physiol Lung Cell Mol Physiol 288, L655-62 (2005).

46. Tonetti, M. S., Imboden, M. A. \& Lang, N. P. Neutrophil migration into the gingival sulcus is associated with transepithelial gradients of interleukin-8 and ICAM-1. J Periodontol 69, 1139-1147 (1998).

47. Edens, H. A. et al. Neutrophil transepithelial migration: evidence for sequential, contact-dependent signaling events and enhanced paracellular permeability independent of transjunctional migration. J Immunol 169, 476-486 (2002).

48. Lau, D. et al. Myeloperoxidase mediates neutrophil activation by association with CD11b/CD18 integrins. Proc Natl Acad Sci USA 102, 431-436 (2005)

49. O’Brien, P. J. Peroxidases. Chem Biol Interact 129, 113-139 (2000).

50. Myeloperoxidase: Current Opinion in Hematology. At http://journals.lww.com/co-hematology/Abstract/2000/01000/ Myeloperoxidase.10.aspx (2000)

51. Teran, L. M., Johnston, S. L., Schröder, J. M., Church, M. K. \& Holgate, S. T. Role of nasal interleukin-8 in neutrophil recruitment and activation in children with virus-induced asthma. Am J Respir Crit Care Med 155, 1362-1366 (1997).

52. Jaovisidha, P., Peeples, M. E., Brees, A. A., Carpenter, L. R. \& Moy, J. N. Respiratory syncytial virus stimulates neutrophil degranulation and chemokine release. J Immunol 163, 2816-2820 (1999).

53. Nash, S., Stafford, J. \& Madara, J. L. Effects of polymorphonuclear leukocyte transmigration on the barrier function of cultured intestinal epithelial monolayers. J Clin Invest 80, 1104-1113 (1987).

54. Parsons, P. E., Sugahara, K., Cott, G. R., Mason, R. J. \& Henson, P. M. The effect of neutrophil migration and prolonged neutrophil contact on epithelial permeability. Am J Pathol 129, 302-312 (1987).

55. Nusrat, A., Parkos, C., Liang, T., Carnes, D. \& Madara, J. Neutrophil migration across model intestinal epithelia: Monolayer disruption and subsequent events in epithelial repair. Gastroenterology 113, 1489-1500 (1997).

56. Kidney, J. C. \& Proud, D. Neutrophil transmigration across human airway epithelial monolayers: mechanisms and dependence on electrical resistance. Am J Respir Cell Mol Biol 23, 389-395 (2000).

57. Yasui, K. et al. Neutrophil-mediated inflammation in respiratory syncytial viral bronchiolitis. Pediatr Int 47, 190-195 (2005).

58. Bardoel, B. W., Kenny, E. F., Sollberger, G. \& Zychlinsky, A. The balancing act of neutrophils. Cell Host Microbe 15, 526-536 (2014).

59. Franz, A. et al. Correlation of viral load of respiratory pathogens and co-infections with disease severity in children hospitalized for lower respiratory tract infection. J Clin Virol 48, 239-245 (2010).

60. DeVincenzo, J. P. et al. Viral load drives disease in humans experimentally infected with respiratory syncytial virus. Am J Respir Crit Care Med 182, 1305-1314 (2010).

61. Houben, M. L. et al. Disease severity and viral load are correlated in infants with primary respiratory syncytial virus infection in the community. J Med Virol 82, 1266-1271 (2010).

62. Hosakote, Y. M., Brasier, A. R., Casola, A., Garofalo, R. P. \& Kurosky, A. Respiratory Syncytial Virus Infection Triggers Epithelial HMGB1 Release as a Damage-Associated Molecular Pattern Promoting a Monocytic Inflammatory Response. J Virol 90, 9618-9631 (2016).

63. Chahar, H. S., Corsello, T., Kudlicki, A. S., Komaravelli, N. \& Casola, A. Respiratory Syncytial Virus Infection Changes Cargo Composition of Exosome Released from Airway Epithelial Cells. Sci Rep 8, 387 (2018).

64. Ren, H., Birch, N. P. \& Suresh, V. An optimised human cell culture model for alveolar epithelial transport. PLoS ONE 11, e0165225 (2016).

65. George, I., Vranic, S., Boland, S., Courtois, A. \& Baeza-Squiban, A. Development of an in vitro model of human bronchial epithelial barrier to study nanoparticle translocation. Toxicol In Vitro 29, 51-58 (2015).

\section{Acknowledgements}

YD was recipient of a Newton fellowship from The Academy of Medical Science (ref 0403). This work was supported by the Great Ormond Street Children's Charity (grant code W1802). This research was supported by the NIHR Great Ormond Street Hospital Biomedical Research Centre. The views expressed are those of the author(s) and not necessarily those of the NHS, the NIHR or the Department of Health. 


\section{Author Contributions}

Y.D. and J.A.H. contributed equally to study design, acquisition and analysis of data, and assembly of the manuscript. C.M.S. and R.L.S. conceived the study, contributed to study design, assembly and final approval of the manuscript.

\section{Additional Information}

Supplementary information accompanies this paper at https://doi.org/10.1038/s41598-018-25167-4.

Competing Interests: The authors declare no competing interests.

Publisher's note: Springer Nature remains neutral with regard to jurisdictional claims in published maps and institutional affiliations.

(c) (i) Open Access This article is licensed under a Creative Commons Attribution 4.0 International License, which permits use, sharing, adaptation, distribution and reproduction in any medium or format, as long as you give appropriate credit to the original author(s) and the source, provide a link to the Creative Commons license, and indicate if changes were made. The images or other third party material in this article are included in the article's Creative Commons license, unless indicated otherwise in a credit line to the material. If material is not included in the article's Creative Commons license and your intended use is not permitted by statutory regulation or exceeds the permitted use, you will need to obtain permission directly from the copyright holder. To view a copy of this license, visit http://creativecommons.org/licenses/by/4.0/.

(c) The Author(s) 2018 